University of Nebraska - Lincoln

DigitalCommons@University of Nebraska - Lincoln

2014

\title{
Heterogeneous Symptom Patterns of Sexually Abused Children in Treatment: Understanding the Complexity of the Problem
}

\author{
Genelle K. Sawyer \\ The Citadel, genelle.sawyer@citadel.edu \\ David J. Hansen \\ University of Nebraska-Lincoln, dhansen1@unl.edu
}

Follow this and additional works at: https://digitalcommons.unl.edu/psychfacpub

Part of the Psychology Commons

Sawyer, Genelle K. and Hansen, David J., "Heterogeneous Symptom Patterns of Sexually Abused Children in Treatment: Understanding the Complexity of the Problem" (2014). Faculty Publications, Department of Psychology. 1035.

https://digitalcommons.unl.edu/psychfacpub/1035

This Article is brought to you for free and open access by the Psychology, Department of at DigitalCommons@University of Nebraska - Lincoln. It has been accepted for inclusion in Faculty Publications, Department of Psychology by an authorized administrator of DigitalCommons@University of Nebraska - Lincoln. 


\title{
Heterogeneous Symptom Patterns of Sexually Abused Children in Treatment: Understanding the Complexity of the Problem
}

\author{
Genelle K. Sawyer ${ }^{1}$ and David J. Hansen ${ }^{2}$ \\ 1. Department of Psychology, The Citadel, Charleston, South Carolina, USA \\ 2. Department of Psychology, University of Nebraska-Lincoln, Lincoln, Nebraska, USA \\ Corresponding author - Genelle K. Sawyer, Department of Psychology, The Citadel, Charleston, SC 29409, email \\ genelle.sawyer@citadel.edu
}

\begin{abstract}
A major challenge for clinicians and researchers is the heterogeneity of the severity and type of symptoms presented by sexually abused youth, including those who are subclinical on traditional clinical measures but still present to treatment. Most research continues to treat sexually abused youth as a single population and has not assessed the outcomes or symptom trajectories of various groups of sexually abused youth. Participants included 107 sexually abused children and their nonoffending parents presenting to a cognitive-behavioral group treatment. A cluster analysis using child and parentreport measures revealed four profiles, including Subclinical, Highly Distressed, Problem Behaviors, and Self-Reported Distress clusters. Hierarchical linear modeling was used to create separate child and parent-report models of weekly symptomatology to examine differential change over the course of treatment. Contrary to expectation, there was little variation in the weekly rates of change for the different symptom groups; however, all groups evidenced a decrease in symptoms over the course of treatment, including the Subclinical cluster.
\end{abstract}

Keywords: child sexual abuse, psychopathology, treatment, cluster analysis

Sexually abused children and adolescents display a considerable breadth of symptoms, including emotional disorders (e.g., anxiety, depression), cognitive disturbances and errors (e.g., poor self-esteem, cognitive distortions, attribution errors, concentration difficulties), 
behavior problems (e.g., substance abuse, self-harm behavior, sexual behavior problems, acting-out behaviors), academic problems, and interpersonal difficulties (e.g., KendallTackett, Williams, \& Finkelhor, 1993; Putnam, 2003). While the majority of youth display difficulties surrounding the abuse, a significant portion exhibit little to no symptomatology (Collin-Vézina, Daigneault, \& Hébert, 2013; Finkelhor \& Berliner, 1995). Studies have found between $21 \%$ and $49 \%$ of sexually abused children may be asymptomatic at the time of their assessment (Kendall-Tackett et al., 1993; Putnam, 2003). Overall, the literature suggests sexually abused youth display a multitude of symptom patterns at varying levels of severity.

Despite this finding, few studies have examined the within-group variability of sexually abused youth. Instead, many studies have treated sexual abuse (SA) as a single phenomenon, assuming homogeneity of their sample by using a variable-oriented approach. To date, only a few studies have utilized a person-oriented approach to examine the withingroup variability of victims of SA (e.g., Bennett, Hughes, \& Luke, 2000; Elhai, Klotz Flitter, Gold, \& Sellers, 2001; Jonzon \& Lindblad, 2006). Only two studies have examined symptom heterogeneity in sexually abused children (Daignault \& Hébert, 2009; Hébert, Parent, Daignault, \& Tourigny, 2006). Hébert and colleagues (2006) examined the profiles of 123 children (110 girls and 13 boys) aged 7 to 13 who were referred for a SA evaluation and four symptom clusters were revealed. The first cluster, the "Anxiety Constellation Group" (33\% of sample), consisted of children with multiple behavioral problems including anxiety, delinquency, and problems with attention. The "Severe Distress Group" (25\% of sample) was characterized by pervasive behavioral and emotional problems, a less cohesive family, and more severe acts of abuse. A third cluster, the "Victims of Less Severe SA Group" ( $26 \%$ of sample), consisted of children who were more likely to experience extrafamilial SA of a shorter duration and were functioning within normal limits. The last cluster, or the "Resilient Group" (16\% of sample), comprised youth who did not show clinically elevated adjustment difficulties but who experienced severe acts of abuse. These children evidenced higher self-esteem, relied less on avoidance coping, and were living in a home with less conflict. While this study was a significant step toward disentangling the complexity of $\mathrm{SA}$, the clusters were derived from parent reports of functioning, and no abuse-specific symptoms (e.g., sexual behavior problems, posttraumatic stress) were assessed.

The second study consisted of 100 females aged 7 to 12 and examined academic, behavioral, and social adaptation at school (Daignault \& Hébert, 2009). Information was obtained from the child, mother, and teacher. Similar to the previous study, four clusters were revealed: (a) academic-specific (15\% of sample) consisted of girls with severe and long-lasting academic problems, whereas social and emotional functioning were within the average range; (b) acting-out/withdrawn ( $16 \%$ of sample) consisted of girls who were academically and socially average but had difficulties with anger, rule breaking, and social withdrawal; (c) polyclinical ( $22 \%$ of sample) comprised girls with significant social problems, academic difficulties, and behavioral issues; and (d) resilient ( $47 \%$ of sample) consisted of girls who were socially competent, performing well academically, and demonstrating minimal emotional and behavioral difficulties. Similar to the previous study it did not use abuse-specific symptoms as clustering variables; however, posttraumatic stress disorder (PTSD), dissociation, and depression were examined across clusters, and significant differences in PTSD 
and dissociation were found. Results of both of these studies highlight the diversity of symptom profiles in CSA, the frequency with which children display no to limited symptoms post disclosure, and the importance of using a person-oriented approach.

Treatment is also unique in that many children are referred for services not because of the symptoms they are displaying but because they experienced the event of SA (Saunders, 2012). In fact, many children receive services after disclosure because of parental fear of damage to their children or as a preventative method against the onset of future difficulties (Finkelhor \& Berliner, 1995). Saywitz, Mannarino, Berliner, and Cohen (2000) posited there are four distinct and sizeable groups that may present to treatment: those who present with (a) detectable difficulties on standardized measures; (b) minor, nonclinically significant symptoms; (c) serious but subdiagnostic levels of psychiatric symptoms including depression, anxiety, sexualized behavior, and posttraumatic stress; and (d) full diagnostic criteria for at least one psychiatric disorder.

The presentation of asymptomatic children to treatment poses a dilemma for clinicians and researchers. It is common practice to provide asymptomatic children with treatment, particularly psychoeducation, despite their lack of symptoms (Saunders, 2012; Saywitz et al., 2000). This is considered to be an important preventative intervention as well as an opportunity to screen for potential risk factors (Saywitz et al., 2000). However, Oellerich (2002) argues treatment for SA should not be routine because (a) not all substantiated cases of abuse really occurred, (b) psychological harm is not the rule, and (c) psychotherapy has not been proven to be effective for everyone. He recommends mental health professionals should not treat the asymptomatic child because "there is no evidence that preventive psychotherapy works" (p. 19).

Unfortunately, there is little research available to inform this issue. In fact, most treatment outcome studies explicitly exclude asymptomatic children to reduce difficulties related to showing positive changes in outcome measures (Finkelhor \& Berliner, 1995), while others simply don't mention the potential presence of these youth. Even though some researchers have explicitly called for the study of asymptomatic children (e.g., Saywitz et al., 2000), no research studies have examined these children over time.

The current study sought to: (a) elucidate the symptom profiles of emotional and behavioral adjustment that are present within a sample of sexually abused children using cluster analysis and (b) examine change over the course of treatment for the obtained clusters. To date, the majority of treatment outcome studies have relied on comprehensive assessments conducted at pre- and post-treatment and have, therefore, been unable to monitor weekly progress or determine specific gains or losses over the course of treatment. This study had the unique advantage of also obtaining weekly symptom reports, which allowed analysis of the subtle changes experienced throughout treatment, even for individuals who did not surpass clinical cutoffs on traditional measures.

\section{Method}

\section{Participants}

Participants included 107 sexually abused children and their nonoffending parents presenting to Project SAFE, a 12-session cognitive-behavioral group treatment (Tavkar \& Hansen, 
2011). Families were selected for participation using the following criteria: (a) the child was 7 to 16 years old, (b) the nonoffending parent assumed a caregiving role (e.g., step parents, foster parents), and (c) the child was a victim of CSA, as determined by a forensic evaluation or department of social services. The single exclusionary criterion was significantly impaired cognitive/intellectual functioning of the child.

Data were collected over a 5-year time period, and participants were primarily referred by the local child advocacy center (CAC). During this time it is estimated approximately 135 youth per year would have been eligible for participation in Project SAFE. Child advocates informed all eligible families, and interested families were contacted by Project SAFE staff. Exact rates of referrals and participation are not available for this time period. During the 5-year time period, 153 youth participated in Project SAFE. Of these, 24 were excluded from the current study because of missing data or having attended less than two sessions of treatment. An additional 22 were excluded because they were siblings of children in the current study, resulting in a final sample of 107 children. Children attended an average of $7.93(S D=2.79)$ treatment sessions.

Eighty-six (80.4\%) youth were girls, and the average child age was $11.69(S D=2.79)$. Regarding racial identity, 85 (79.4\%) victims were White, seven (6.5\%) were African American, three $(2.8 \%)$ were Native American, three $(2.8 \%)$ were Latino American, eight $(7.5 \%)$ were biracial, and one $(.9 \%)$ was multiracial. Of the nonoffending caregivers, the mean age was $36.87(S D=7.48$; range of 23 to 72$)$. The majority of nonoffending caregivers were a biological parent: 81 (75.7\%) biological mothers and 16 (15.0\%) biological fathers. The large majority $(79.4 \%)$ identified as White. The sample was predominantly lower to lower-middle class, and just under half were married.

\section{Procedures}

Data for this study come from an ongoing clinical treatment program (Project SAFE). Project SAFE is a standardized, manual-based group treatment program for sexually abused youth (ages 7 to 16) and their nonoffending caregivers. Procedures used were psychoeducational, skill building, problem-solving, and supportive. Youth and parent groups met concurrently for 1290 -minute sessions. Youth groups were co-ed and divided into separate child and adolescent groups to ensure topics and materials were developmentally appropriate. Groups were cofacilitated by therapists who were doctoral students in the clinical psychology program at the University of Nebraska-Lincoln and supervised by licensed clinical psychologists. Comprehensive evaluations have been conducted that support positive parent and child outcomes post-treatment (e.g., Hubel et al., in press; Hubel, Maldonado, Tavkar, Hansen, \& Flood, 2011). Subjective evaluations revealed the treatment goals, procedures, and outcomes were acceptable, relevant, and helpful to the families (Hsu, 2003).

Families referred were screened based on inclusion and exclusion criteria. Caregivers gave informed consent and children provided assent. Families completed the Weekly Problems Scales at the pretreatment assessment and weekly throughout treatment. All additional measures were completed only at the pretreatment assessment. 


\section{Child Report Measures}

\section{Children's Depression Inventory}

The Children's Depression Inventory (CDI; Kovacs, 1992) is a 27-item self-report measure that assesses depression in children ages 7 to 17. Respondents are instructed to rate how they felt in the past two weeks. This measure has been found to be reliable with adequate internal consistency ranging from .71 to .89 . Test-retest reliability has also been established (.72 to .84$)$.

\section{Children's Fears Related to Victimization}

The CFRV, a 27-item subscale of the Fear Survey Schedule for Children-Revised (FSSC-R; Ollendick, 1983; Wolfe \& Wolfe, 1986) is a self-report measure for children aged 7 to 12 years that assesses situations that may be distressing to sexually abused children (e.g., sleeping alone, saying "no" to an adult). The CFRV consists of two subscales: sex-associated fears and interpersonal discomfort. Both scales have been found to have high internal reliability, though their validity has not yet been established (Feindler, Rathus, \& Silver, 2003).

\section{Children's Impact of Traumatic Events-Revised}

The Children's Impact of Traumatic Events-Revised (CITES-R; Wolfe, Gentile, Michienzi, Sas, \& Wolfe, 1991) is a structured interview measuring the impact of sexual abuse from the child's perspective across areas of Posttraumatic Stress, Abuse Attributions, Social Reactions, and Eroticism. Moderate support has been demonstrated for the psychometric properties of the CITES-R (Chaffin \& Shultz, 2001).

\section{Revised Children's Manifest Anxiety Scale}

The Revised Children's Manifest Anxiety Scale (RCMAS; Reynolds \& Richmond, 1985) is a 37-item self-report measure that assesses general anxiety in children and adolescents ages 6 to 19. The Total Anxiety score is based on 28 items. Reliability has been established (alpha $=.83)$.

Weekly Problems Scale-Child Version

The Weekly Problems Scale-Child Version (WPS-C; Sawyer, Futa, Hecht, \& Hansen, 2006) is a brief, efficient means of assessing multiple domains of child functioning relevant to youth with a history of SA. The scale consists of 11 statements (e.g., "I feel sad," "I get along with my friends"), and children are asked to mark one of six responses, ranging from never to all of the time, that best describe the past week. Good internal consistency, temporal stability, and construct validity have been demonstrated for the WPS-C (Sawyer, Tsao, Hansen, \& Flood, 2006). An alpha coefficient of .79 was yielded for the WPS-C Total Scale.

\section{Parent Report Measures}

\section{Child Behavior Checklist}

The Child Behavior Checklist-Parent Report Form (CBCL; Achenbach, 1991) is a 113-item checklist assessing parents' perceptions of social competence and behavioral problems of 
their children ages 4 to 18. Parents rate the presence of problem behaviors in the previous six months on a three-point scale ranging from 0 (not true) to 2 (very true). The CBCL is an instrument with well-established reliability and validity (Achenbach, 1991).

\section{Child History Form}

The Child History Form (CHF) is an unstructured interview developed by Project SAFE that collects abuse-related information. The CHF is completed by a therapist while parents provide abuse information in their own words. Abuse characteristics gathered include age at onset and end of abuse, duration, relationship to perpetrator, frequency, number of times abused, and nature of the abuse.

Child Sexual Behavior Inventory

The initial 83 participants completed the CSBI 2nd Edition (Friedrich et al., 1992), while the remaining 23 participants completed the updated CSBI 3rd Edition (Friedrich et al., 2001). CSBI-2 scores were converted (by multiplying the CSBI-2 Total by .06) to be consistent with the CSBI-3 scoring. The CSBI is completed by parents on the frequency of sexual behaviors pertaining to sexual aggression, self-stimulation, gender-role behavior, and personal boundary violation observed. The CSBI-3 demonstrates good reliability (e.g., alpha coefficient of .93 for children with a history of SA) and validity (Friedrich et al., 2001).

\section{Weekly Problems Scale-Parent Version}

The Weekly Problems Scale-Parent Version (WPS-P; Sawyer et al., 2006) is a companion to the WPS-C. It consists of 15 statements (e.g., "During the past 7 days my child appeared unhappy, sad, or depressed," "During the past 7 days my child argued or fought with others"). Parents are asked to rate each statement on a scale from 1 (never) to 10 (always). Good internal consistency, temporal stability, and construct validity have been demonstrated for the WPS-P (Sawyer et al., 2006). Analyses yielded alpha coefficients .86 for the WPS-P Total Scale.

\section{Results}

\section{Abuse Information}

The perpetrators included 57 (44.5\%) family members (e.g., biological fathers, siblings, and other relatives) and 71 (55.5\%) nonfamily members (e.g., neighbor, family friends). Only 7 experienced a noncontact form of SA (e.g., exposure, pornography, sexually explicit talk). Forty-nine victims (45.8\%) experienced anal, oral, or vaginal penetration. The most common behavior identified in this sample was fondling $(70.1 \%)$. Nonoffending parents estimated $43.9 \%$ experienced 1 or 2 abuse incidents, and $43.0 \%$ endured multiple acts of abuse. The duration of the abuse ranged from 1 time to 7.5 years, with a mean duration of 12.7 months $(S D=18.6)$. 


\section{Cluster Analysis}

\section{Cluster Formation}

Hierarchical cluster analysis was performed on seven measures reflecting various areas of adjustment that have been linked with CSA: (a) CBCL Externalizing Problems subscale, (b) CBCL Internalizing Problems subscale, (c) CSBI Total, (d) CITES-R PTSD subscale, (e) CDI Total, (f) RCMAS Total Anxiety, and (g) the CFRV Total. Original means and standard deviations are in Table 1 . All scores were transformed to standardized $z$-scores for the cluster analysis. Cases were linked using Ward's method and Squared Euclidean distance was the measure of similarity.

Table 1. Means and Standard Deviations for Measures of Adjustment

\begin{tabular}{lccc}
\hline Measure & $M$ & Range & $S D$ \\
\hline Children's Depression Inventory Total & 55.82 & $(34-92)$ & 14.55 \\
Children's Fears Related to Victimization Total & 52.23 & $(27-73)$ & 11.01 \\
Children's Manifest Anxiety Scale-Revised Total Anxiety $^{\text {CITES-R Post Traumatic Stress Disorder Scale Total }}$ & 53.01 & $(22-92)$ & 14.28 \\
CBCL Internalizing Scale Total* $^{*}$ & 26.85 & $(2-49)$ & 10.30 \\
CBCL Externalizing Scale Total $^{*}$ & 62.82 & $(33-82)$ & 10.83 \\
Children's Sexual Behavior Inventory Total Score $^{*}$ & 61.72 & $(32-91)$ & 12.30 \\
\hline
\end{tabular}

Note: $\mathrm{N}=107 .{ }^{*}$ Clinical cutoff of $>70$.

The cluster profile solution was chosen based on an examination of the agglomeration schedule and a visual examination of the dendogram. The percentage of change between coefficients from stages of clusters in the agglomeration schedule was examined. Prior to the stage in which 4 clusters were created, the increase in within-cluster variability was less than $9 \%$. However, the stage in which 5 clusters combined into 4 clusters resulted in a $16.7 \%$ increase, suggesting a 4 -cluster solution as the best fit. A visual examination of the dendogram also supported a 4-cluster solution. To test the stability of the solution, additional analyses were conducted. Both the within-groups average linkage and K-means cluster analyses suggested similar solutions with $85 \%$ and $77.6 \%$, respectively, of the children being placed in the same group.

\section{Cluster Description}

For the 4-cluster solution, 18 children (16.8\%) fell into the first cluster, 34 children $(31.8 \%)$ the second, $30(28.0 \%)$ in the third, and $25(23.4 \%)$ in the fourth. Figure 1 provides a graphical representation of the four cluster profiles. The first cluster was the smallest and labeled "Highly Distressed." This cluster was characterized by significant elevations on all measures. The second, largest cluster was labeled "Problem Behaviors" because of the elevated scores on the CBCL Internalizing Scale, CBCL Externalizing Scale, and CSBI Total. The third cluster, termed "Subclinical," revealed a profile in which children did not show clinically elevated scores. The last cluster, labeled "Self-Reported Distress," was characterized by moderate levels of depression and anxiety as reported by the children. 


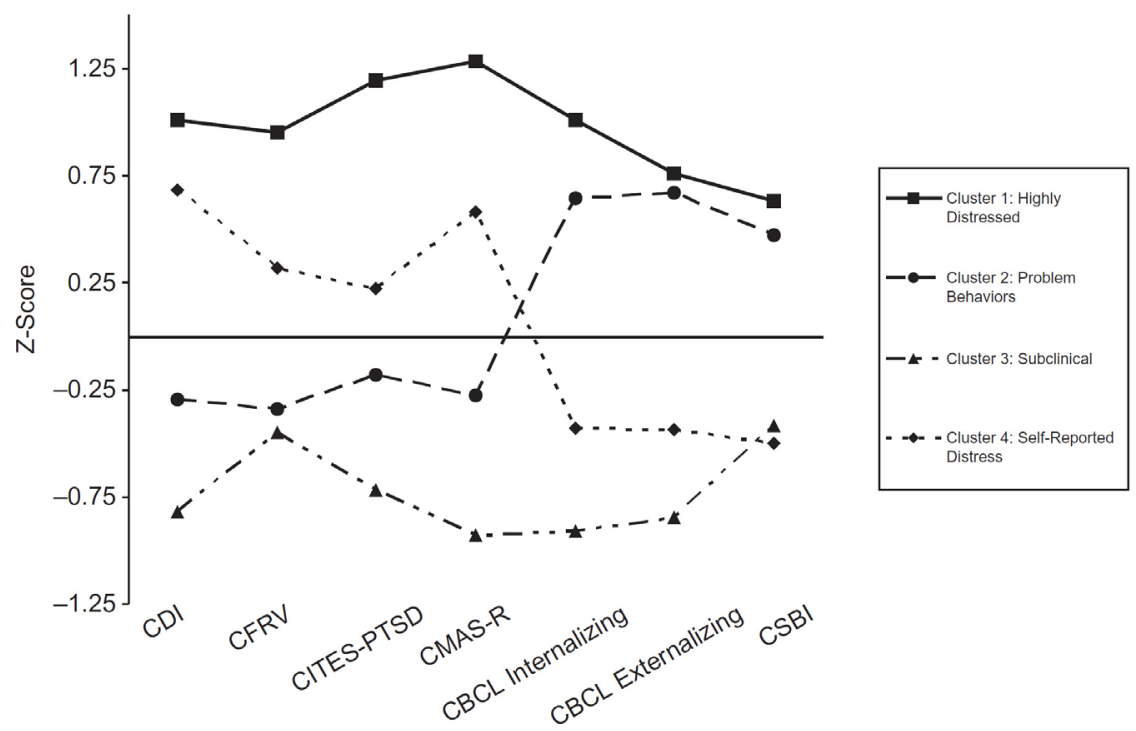

Figure 1. Clinical profiles (based on $z$ scores) of self-report and parent-report measures.

Table 2 presents the results of one-way ANOVAs on the four groups for each measure used in the cluster analysis. ANOVAs revealed significant differences across the profiles on all variables. LSD pairwise comparisons results indicated multiple significant differences across clusters. The relationships of child demographic variables (age and gender) and abuse characteristics (severity, duration, relationship of perpetrator, and number of perpetrators) with the clinical profiles were then examined. The only significant relationship was with abuse severity, $\chi^{2}(3)=10.70, p>.05$. Children in the Highly Distressed cluster experienced more severe forms of abuse (oral, anal, and/or vaginal sex). Children in the Subclinical and Self-Reported Distress clusters were more likely to have experienced less severe acts of abuse (e.g., fondling, viewing pornography).

Table 2. Between-Group Differences Means and Standard Deviations for Measures of Adjustment Across Four Clusters

\begin{tabular}{|c|c|c|c|c|c|c|c|c|c|}
\hline \multirow[b]{2}{*}{ Measure } & \multicolumn{2}{|c|}{$\begin{array}{c}\text { Cluster } 1 \\
\text { Highly } \\
\text { Distressed } \\
(n=18)\end{array}$} & \multicolumn{2}{|c|}{$\begin{array}{c}\text { Cluster } 2 \\
\text { Problem } \\
\text { Behaviors } \\
(n=34)\end{array}$} & \multicolumn{2}{|c|}{$\begin{array}{l}\text { Cluster } 3 \\
\text { Subclinical } \\
\quad(n=30)\end{array}$} & \multicolumn{2}{|c|}{$\begin{array}{c}\text { Cluster } 4 \\
\text { Self-Reported } \\
\text { Distress } \\
(n=25)\end{array}$} & \multirow[b]{2}{*}{$\mathrm{F}^{*}$} \\
\hline & $M$ & $S D$ & $M$ & $S D$ & $M$ & $S D$ & $M$ & $S D$ & \\
\hline CDI Total & $70.28 \mathrm{a}$ & 12.57 & $51.44 \mathrm{~b}$ & 9.74 & $43.97 \mathrm{c}$ & 5.59 & $65.60 \mathrm{a}$ & 13.99 & 33.13 \\
\hline CFRV Total & $62.72 a$ & 7.48 & $48.47 \mathrm{~b}$ & 9.75 & $47.30 \mathrm{~b}$ & 8.93 & $55.72 c$ & 11.09 & 12.83 \\
\hline CITES-R PTSD Scale & $39.11 a$ & 5.47 & $25.09 \mathrm{~b}$ & 8.40 & $19.53 \mathrm{c}$ & 9.58 & $29.20 \mathrm{~b}$ & 7.03 & 23.39 \\
\hline CMAS-R Total & $71.00 \mathrm{a}$ & 10.27 & $49.03 b$ & 8.69 & $39.93 c$ & 10.42 & $61.16 \mathrm{~d}$ & 6.54 & 53.39 \\
\hline CBCL Internalizing Scale & $73.44 a$ & 4.94 & $64.47 \mathrm{~b}$ & 7.57 & $52.90 \mathrm{c}$ & 7.62 & $58.04 \mathrm{~d}$ & 7.61 & 45.07 \\
\hline CBCL Externalizing Scale & $70.89 a$ & 9.03 & $69.82 a$ & 8.47 & $51.43 \mathrm{~b}$ & 11.04 & $56.44 c$ & 6.91 & 31.03 \\
\hline CSBI Total & $14.24 \mathrm{a}$ & 12.71 & $12.71 \mathrm{a}$ & 10.13 & $4.27 \mathrm{~b}$ & 5.95 & $3.49 \mathrm{~b}$ & 3.05 & 10.9 \\
\hline
\end{tabular}

${ }^{*} d f=3,103 ; p<.001$. Means with dissimilar subscripts differ significantly at $p<.05$. 


\section{Hierarchical Linear Modeling}

Hierarchical linear modeling (HLM) was used to examine the differential rates of change for each cluster over treatment. To assess the effects of cluster membership over the course of treatment, two hierarchical models were developed. The dependent variable in each model was the repeated measure of symptoms (WPS-C Total and WPS-P Total) at each of the 12 weeks of treatment. The level-2 predictor was a child's cluster membership, with the Subclinical Cluster being used as the reference group.

\section{Change in Symptoms by Child Report}

First, an unconditional model was examined to describe how child-reported symptoms (as measured by the WPS-C) changed over time, without examining the influence of cluster placement. Linear and quadratic effects were included. Results can be seen in Table 3 . The coefficient for the WPS-C was $30.35(t=34.90, p<.001)$, which is the average score on the WPSC at the pre-treatment assessment. There was significant variability in the baseline scores between children (Wald $Z=5.84, p<.001)$. The slope coefficient was negative $(t=-4.52$, $p<.001$ ), and there was significant growth rate variability between children (Wald $Z=3.69$, $p<.001)$. Finally, the quadratic coefficient was positive $(t=3.00, p<.01)$, and there was significant variability in acceleration (Wald $Z=2.87, p<.01$ ). However, the residual variance between linear and quadratic growth rates was not significant (Wald $Z=-3.25, p<.01$ ). Overall, results indicate that, on average, symptoms decreased over the course of treatment, with the greatest change occurring in the initial sessions of treatment.

Because the unconditional growth model analysis indicated individuals differed, a level-2 covariate (cluster membership) was added, with the Subclinical cluster being used as the reference group. Results are presented in Table 3. Results suggested the typical child in the Subclinical cluster experienced little change over the course of treatment. Initial status coefficients of the remaining three clusters were all significantly greater than the Subclinical cluster. Results continued to indicate there was significant variability in the initial status scores (Wald $Z=5.08 ; p<.001)$. Only the Highly Distressed cluster's linear $\left(\beta_{11}=-1.73\right.$, $t=3.01, p<.01)$ and quadratic $\left(\beta_{21}=.10, t=2.83, p<.01\right)$ growth rates were significantly different from that of the Subclinical cluster. Results continued to indicate there was significant variability in the linear and quadratic growth rates (Wald $\mathrm{Z}=3.45, p<.01$; Wald $\mathrm{Z}$ $=2.54, p<.05$, respectively). Finally, there was nonsignificant covariance between intercepts and growth rates but significant negative covariance between linear and quadratic growth rates (Wald $Z=-2.96, p<.01$ ). 
Table 3. Growth Models for Weekly Problems Scale-Child Version

\begin{tabular}{|c|c|c|c|c|}
\hline \multirow[b]{2}{*}{ Effects } & \multicolumn{2}{|c|}{ Unconditional Model } & \multicolumn{2}{|c|}{ Conditional Model } \\
\hline & Coefficient & $S E$ & Coefficient & $S E$ \\
\hline \multicolumn{5}{|l|}{ Fixed Effects } \\
\hline Initial status & $30.35^{* * *}$ & .8 & & \\
\hline Subclinical cluster & & & $22.80^{* *}$ & 1.18 \\
\hline Highly Distressed cluster & & & $16.05^{* *}$ & 1.89 \\
\hline Problem Behavior cluster & & & $6.27^{* *}$ & 1.64 \\
\hline Self-Reported Distress cluster & & & $11.88^{* *}$ & 1.78 \\
\hline Linear change & $-.92^{* * *}$ & .20 & & \\
\hline Subclinical cluster & & & -.33 & .37 \\
\hline Highly Distressed cluster & & & -1.73 & .57 \\
\hline Problem Behavior cluster & & & -.54 & .51 \\
\hline Self-Reported Distress cluster & & & -.39 & .55 \\
\hline Quadratic change & .04 & .01 & & \\
\hline Subclinical cluster & & & .00 & .02 \\
\hline Highly Distressed cluster & & & $.10^{*}$ & .04 \\
\hline Problem Behavior cluster & & & .04 & .03 \\
\hline Self-Reported Distress cluster & & & .01 & .03 \\
\hline \multicolumn{5}{|l|}{ Random Effects } \\
\hline Intercept & $59.96^{* * *}$ & 10.27 & $26.37^{* * *}$ & 5.19 \\
\hline Linear Growth & $2.08^{* * *}$ & .56 & $1.76^{* *}$ & .51 \\
\hline Quadratic Growth & $.01^{* *}$ & .00 & $.01^{*}$ & .00 \\
\hline Intercept $\times$ Linear Growth & -2.50 & 1.71 & .18 & 1.12 \\
\hline Intercept $\times$ Quadratic Growth & .12 & .11 & -.02 & .07 \\
\hline Linear Growth $\times$ Quadratic Growth & $-.11^{* * *}$ & .04 & -.09 & .03 \\
\hline
\end{tabular}

Note: Unconditional Model -2 Log Likelihood = 5112.14. Conditional Model -2 Log Likelihood $=5044.48$. ${ }^{*} p<.05,{ }^{* *} p<.01,{ }^{* * *} p<.001$

Because this model is nested within the unconditional model, the two models can be compared using a likelihood-ratio test. Results suggest the model significantly improved with the addition of cluster membership, $\chi^{2}(9)=67.66, p<.01$. When visually comparing the two models, the intercept variance decreased substantially from 59.96 to 26.37 , suggesting cluster membership accounted for a large proportion of the initial intercept variance. Similarly, the slope variance decreased from 2.08 to 1.76 , suggesting the inclusion of cluster membership affected the fit of the model. In contrast, the quadratic growth variance is virtually the same, indicating cluster membership does little to account for individual differences in quadratic growth rates.

\section{Change in Symptoms by Parent Report}

Following a similar strategy, an unconditional model was examined to describe how WPS-P scores changed over time. Linear and quadratic effects were included; however, quadratic effects were not significant in the model and were, therefore, excluded. Results can be seen in Table 4. The coefficient for the WPS-P was $58.73(t=40.24, p<.001)$. There was significant variability in the initial status scores between children (Wald $Z=5.41, p<.001$ ). The slope coefficient was negative $(t=5.21, p<.001)$, and there was significant growth rate variability 
(Wald $\mathrm{Z}=2.92, p<.01$ ). The residual variance was not significant. Results indicate that, on average, parents report linear decreases in symptoms during treatment.

Cluster membership was added to the model as a level-2 covariate. The mean WPS-P initial status for the Subclinical cluster was 49.55, $t=23.84, p<.001$. The other three clusters had initial status coefficients that were all significantly greater (see Table 4 ). The growth rate for the Subclinical cluster was $-.63, t=-3.04, p<.01$, suggesting, on average, children in this cluster decrease .63 points on the WPS-P each week of treatment. None of the other clusters had a growth rate that was significantly different. There were statistically significant differences across children with respect to their initial status, $\mathrm{s}^{2} \mathrm{i}=94.29, \mathrm{Wald} \mathrm{Z}=4.93$, $p<.001$, as well as significant growth rate variance, $\mathrm{s}^{2} \mathrm{~s}=.48$, Wald $\mathrm{Z}=2.91, p<.01$. Last, there was a nonsignificant negative covariance between intercepts and growth rates.

Table 4. Conditional Growth Model for Weekly Problems Scale-Parent Version

\begin{tabular}{|c|c|c|c|c|}
\hline \multirow[b]{2}{*}{ Effects } & \multicolumn{2}{|c|}{ Unconditional Model } & \multicolumn{2}{|c|}{ Conditional Model } \\
\hline & Coefficient & $S E$ & Coefficient & $S E$ \\
\hline \multicolumn{5}{|l|}{ Fixed Effects } \\
\hline Initial status & $58.73^{* * *}$ & 1.46 & & \\
\hline Subclinical cluster & & & $49.55^{* * *}$ & 2.08 \\
\hline Highly Distressed cluster & & & $16.65^{* * *}$ & 3.58 \\
\hline Problem Behavior cluster & & & $17.33^{* * *}$ & 3.14 \\
\hline Self-Reported Distress cluster & & & $7.59^{*}$ & 3.27 \\
\hline Linear change & $-.59^{* * *}$ & .11 & & \\
\hline Subclinical cluster & & & $-.63^{* *}$ & .21 \\
\hline Highly Distressed cluster & & & .11 & .33 \\
\hline Problem Behavior cluster & & & -.21 & .31 \\
\hline Self-Reported Distress cluster & & & .20 & .31 \\
\hline \multicolumn{5}{|l|}{ Random Effects } \\
\hline Intercept & $150.27^{* * *}$ & 27.80 & $94.29^{* * *}$ & 19.12 \\
\hline Linear Growth & $.47^{* *}$ & .16 & $.49^{* *}$ & .17 \\
\hline Level-1 & -1.4 & 1.72 & -1.37 & 1.48 \\
\hline
\end{tabular}

Note: Unconditional Model -2 Log Likelihood $=6258.94$. Conditional Model -2 Log Likelihood $=6223.11$. ${ }^{*} p<.05,{ }^{* *} p<.01,{ }^{* * *} p<.001$

The models were significantly different using a likelihood-ratio test, $\chi^{2}(6)=6258.94-$ $6223.11=35.83, p<.01$, suggesting the model was improved with the addition of cluster membership. When visually comparing the two models, the intercept variance decreased from 150.27 to 94.29 , suggesting cluster membership accounts for a large proportion of the initial intercept variance. In contrast, the slope variance is virtually the same, indicating cluster membership does little to account for individual growth rate differences.

\section{Discussion}

A major challenge for clinicians and researchers is the heterogeneity of the severity and type of symptoms presented by sexually abused youth, including those who do not surpass clinical thresholds on traditional measures but still present to treatment. Hierarchical cluster analyses of scores from parent and child-report measures identified four patterns 
of adjustment associated with CSA. Similar to expectations, one cluster was characterized by children who did not show clinically elevated scores on any clinical measures. The percentage of children who were subclinical in our sample (28\%) was consistent with previous findings, which have ranged from $21 \%$ to $49 \%$ (Kendall-Tackett et al., 1993). The second cluster, Highly Distressed, consisted of children who displayed multiple behavioral and emotional problems as per both parent and child report.

The Problem Behaviors cluster was the largest and consisted of children who displayed clinically significant emotional and behavioral problems as measured by parent-report measures only, which are based primarily on observable behaviors the child displays. The last cluster was labeled the Self-Reported Distress cluster because children reported moderate levels of depression and anxiety while parents reported no significant symptoms. These clusters overlap somewhat with those identified in previous studies (Daignault \& Hébert, 2009; Hébert et al., 2006) in that there was a cluster of subclinical or resilient children as well as a cluster of highly distressed or polyclinical children. In addition, across these studies more children were identified as resilient or subclinical $(28 \%-47 \%)$ than were highly symptomatic across multiple domains (16\%-25\%). Inconsistency across the other clusters was likely partially as a result of the different variables used by each study in the cluster analyses, variation in reporters of information, and specific populations used in the studies (e.g., presenting to forensic evaluation versus presenting to treatment).

Interestingly, differences between the Problem Behaviors cluster and the Self-Reported Distress cluster appear to be potentially related to the identity of the informant. Previous research has suggested agreement between parent and child reports of symptoms are modest (e.g., Achenbach, McConaughty, \& Howell, 1987; Phares, Compas, \& Howell, 1989). However, in the current study, parents and children generally agreed about child symptoms in two of the clusters. An alternative explanation may be related to the types of assessment measures used in the study. All information obtained from children was related to internalizing problems such as anxiety, trauma symptoms, and depression, while parent measures focused on observable behaviors. The choice of measures was consistent with previous research suggesting children are better reporters about their internal states whereas parents are better reporters of observable behaviors (e.g., Kolko \& Kazdin, 1993). Therefore, the clusters likely represent symptoms actually displayed by the children and not merely the identity of the informant.

Overall, results consistently supported the validity and meaningfulness of each cluster, suggesting sexually abused children are a heterogeneous population who display a wide array of behavioral and emotional symptoms following disclosure of SA. These results, therefore, further support the notion of using person-oriented approaches to further understand and recognize the complexity of this population.

The second question of the study examined differential change over the course of treatment for each cluster using HLM. In general, the models supported the validity of the clusters. Initially, unconditional parent and child-report models indicated: (a) symptoms decreased over the course of treatment, (b) there was significant variability in initial symptom presentation, and (c) rates of change during treatment differed across clusters. Both models were enhanced when cluster membership was included as a predictor suggesting presenting symptom profiles have meaningful implications for treatment response and 
outcome. However, contrary to expectations, rates of change over the course of treatment showed little variability across clusters. It should be noted the purpose of this study was to examine the weekly rates of change over the course of treatment for symptom clusters, not the differences at pre and posttreatment. Therefore, one cannot draw the conclusion that because of similar rates of change, there are no differences from pre to posttreatment among the clusters. It will be important for future studies to examine posttreatment differences between clusters.

While including cluster membership provided a better fitting model and reduced the variance, significant intercept and slope variance still remained, suggesting other factors may account for individual variability in symptom presentation and treatment response. Hébert and colleagues (2006) underscored the importance of protective factors (e.g., coping strategies, self-esteem) in helping youth overcome the trauma associated with sexual abuse. Other studies have indicated family factors, child cognitions and attributions, and demographic and environmental factors may mediate outcome (e.g., Cohen \& Mannarino, $1996,2000)$. Future studies should aim to highlight these variables.

The current study also sought to examine the experience of subclinical children over the course of treatment. A significant portion of children entering the current treatment program were in fact displaying no reported clinical symptoms, and results suggest they evidenced a linear decrease in symptoms over treatment (per child report). However, it is unclear how clinically meaningful this change is, given they already displayed normal levels of symptoms. While it is difficult to draw firm conclusions about the effectiveness of this treatment for the subclinical children, results suggested treatment, in general, was not harmful or detrimental, as Oellerich (2002) has argued. It will be important for future studies to continue to include this group in treatment outcome studies to further examine their response. Furthermore, studies should seek to understand the potential benefits for participating in treatment, as most professionals have relied on anecdotal information and theory rather than data to argue for their inclusion in treatment.

Because the sample consisted only of families seeking treatment services, the symptom clusters may not generalize to a sample of nontreatment seeking sexually abused children. However, given the limited exclusionary criteria, it is likely this population is very similar to that of treatment seeking sexually abused children in the general population. Even though the sample of 107 children and their parents was larger than many studies of CSA, the sample size and small $n$ in some clusters still limited the extent of analyses that could be conducted. Studies with larger samples may allow for the inclusion of variables (e.g., gender, age, family variables, child attributions and cognitions, and coping strategies) that influence differences in treatment response. In addition, the study utilized the Weekly Problems Scales to obtain weekly ratings of child symptoms. While previous research has offered preliminary support for this measure (Sawyer et al., 2006), limited information exists about its ability to detect and examine subtle changes in symptoms over the course of treatment.

Overall, these results indicate sexually abused children are a heterogeneous group who display a wide variety of symptoms, and research designs must take this variability into account when examining the impact of, and treatment response for, sexual abuse. Given this is the first study of its kind using a sample of sexually abused children in treatment, it 
will be important for future studies to continue to use multivariate analyses to examine the differential needs and treatment response of sexually abused youth in order to assist in the creation of effective and efficient interventions.

Acknowledgment - This research was supported by a Melissa Institute dissertation grant awarded to the first author.

\section{References}

Achenbach, T. M. (1991). The Child Behavior Checklist manual. Burlington, VT: The University of Vermont.

Achenbach, T. M., McConaughy, S. H., \& Howell, C. T. (1987). Child/adolescent behavioral and emotional problems: Implications of cross-informant correlations for situational specificity. Psychological Bulletin, 101, 213-232.

Bennett, S. E., Hughes, H. M., \& Luke, D. A. (2000). Heterogeneity in patterns of child sexual abuse, family functioning, and long-term adjustment. Journal of Interpersonal Violence, 15, 134-157.

Chaffin, M., \& Shultz, S. (2001). Psychometric evaluation of the Children's Impact of Traumatic Events Scale-Revised. Child Abuse \& Neglect, 25, 401-411.

Cohen, J. A., \& Mannarino, A. P. (1996). Factors that mediate treatment outcome of sexually abused preschool children. Journal of the American Academy of Child and Adolescent Psychiatry, 34, 14021410.

Cohen, J. A., \& Mannarino, A. P. (2000). Predictors of treatment outcome in sexually abused children. Child Abuse \& Neglect, 24, 983-994.

Collin-Vézina, D. Daigneault, I., \& Hébert, M. (2013). Lessons learned from child sexual abuse research: Prevalence, outcomes, and preventive strategies. Child and Adolescent Psychiatry and Mental Health, 7, 1-9.

Diagnault, I. V., \& Hébert M. (2009). Profiles of school adaptation: Social, behavioral, and academic functioning in sexually abused girls. Child Abuse \& Neglect, 33, 102-115.

Elhai, J. D., Klotz Flitter, J. M., Gold, S. N., \& Sellers, A. H. (2001). Identifying subtypes of women survivors of childhood sexual abuse: An MMPI-2 cluster analysis. Journal of Traumatic Stress, 14, 157-175.

Feindler, E., Rathus, J., \& Silver, L. (2003). Assessment of family violence: A handbook for research and practitioners. Washington, DC: American Psychological Association.

Finkelhor, D., \& Berliner, L. (1995). Research on the treatment of sexually abused children: A review and recommendations. Journal of the American Academy of Child and Adolescent Psychiatry, 34, 14081423.

Friedrich, W. N., Fisher, J. L., Dittner, C. A., Acton, R., Berliner, L., Butler, J., . . Wright, J. (2001). Child Sexual Behavior Inventory: Normative, psychiatric, and sexual abuse comparisons. Child Maltreatment, 6 , 37-49.

Friedrich, W. N., Grambsch, P., Damon, L., Hewitt, S. K., Koverola, C., Lang, R. A., . . Broughton, D. (1992). Child Sexual Behavior Inventory normative and clinical comparisons. Psychological Assessment, 4, 303-311.

Hébert, M., Parent, N., Daignault, I. V., \& Tourigny, M. (2006). A typological analysis of behavioral profiles of sexually abused children. Child Maltreatment, 11, 203-216. 
Hubel, G. S., Campbell, C., West, T., Friendenberg, S., Schreier, A., Flood, M. F., \& Hansen, D. J. (in press). Child advocacy center based group treatment for child sexual abuse: Initial symptom presentation, outcomes, and client satisfaction. Journal of Child Sexual Abuse.

Hubel, G. S., Maldonado, R. C., Tavkar, P., Hansen, D. J., \& Flood, M. F. (2011). Group treatment for a sexually abused child and a non-offending caregiver: Case study and discussion. Clinical Case Studies, 10, 360-375. doi: 10.1177/1534650111422376

Hsu, E. (2003). Parallel group treatment for sexually abused children and their nonoffending parents: An examination of treatment integrity and child and family outcome and satisfaction (Unpublished doctoral dissertation). University of Nebraska-Lincoln, Lincoln, NE.

Jonzon, E., \& Lindblad, F. (2006). Risk factors and protective factors in relation to subjective health among adult female victims of child sexual abuse. Child Abuse \& Neglect, 30, 127-143.

Kendall-Tackett, K. A., Williams, L. M., \& Finkelhor, D. (1993). Impact of sexual abuse on children: A review and synthesis of recent empirical studies. Psychological Bulletin, 113, 164-180.

Kolko, K. J., \& Kazdin, A. E. (1993). Emotional/behavioral problems in clinic and nonclinic children: Correspondence among child, parent, and teacher reports. Journal of Child Psychology and Psychiatry, 34, 991-1006.

Kovacs, M. (1992). Children's Depression Inventory. North Tonawanda, NY: MultiHealth Systems.

Oellerich, T. (2002). The case against the routine provision of psychotherapy to children/adolescents labeled "sexually abused." Sexuality \& Culture: An Interdisciplinary Quarterly, 6, 3-24.

Ollendick, T. H. (1983). Reliability and validity of the Revised Fear Survey Schedule for Children (FSSC-R). Behaviour Research and Therapy, 21, 685-692.

Phares, V., Compas, B. E., \& Howell, D. C. (1989). Perspectives on child behavior problems: Comparisons of children's self-reports with parent and teacher reports. Psychological Assessment: A Journal of Consulting and Clinical Psychology, 1, 68-71.

Putnam, F. W. (2003). Ten-year research update review: Child sexual abuse. Journal of the American Academy of Child \& Adolescent Psychiatry, 42, 269-278.

Reynolds, C. R., \& Richmond, B. O. (1985). Revised Children's Manifest Anxiety Scale Manual. Los Angeles, CA: Western Psychological Services.

Saunders, B. E. (2012). Determining best practice for treating sexually victimized children. In P. Goodyear-Brown (Ed.), Handbook of child sexual abuse: Identification, assessment and treatment (pp. 173-197). Hoboken, NJ: John Wiley \& Sons.

Sawyer, G. K., Futa, K. T., Hecht, D. B., \& Hansen, D. J (2006). Manual for the Weekly Problems Scales: Parent and child versions. Lincoln, NE: University of Nebraska-Lincoln Department of Psychology.

Sawyer, G. K., Tsao, E. H., Hansen, D. J., \& Flood, M. F. (2006). Weekly Problems Scales: Instruments for sexually abused youth and their nonoffending parents in treatment. Child Maltreatment, 11, 34-48.

Saywitz, K. J., Mannarino, A. P., Berliner, L., \& Cohen, J. A. (2000). Treatment for sexually abused children and adolescents. American Psychologist, 55, 1040-1049.

Tavkar, P., \& Hansen, D. J. (2011). Interventions for families victimized by child sexual abuse: Clinical issues and approaches for child advocacy center-based services. Aggression and Violent Behavior, 16, 188-199. doi: 10.1016/j.avb.2011.02.005

Wolfe, V. V., Gentile, C., Michienzi, T., Sas, L., \& Wolfe, D. A. (1991). The Children's Impact of Traumatic Events Scale: A measure of post-sexual abuse PTSD symptoms. Behavioral Assessment, 13, 359-383. 
Wolfe, V. V., \& Wolfe, D. A. (1986). The Sexual Abuse Fear Evaluation (SAFE): A subscale for the Fear Survey Schedule for Children-Revised. Unpublished questionnaire. Children's Hospital of Western Ontario, London, Ontario.

\section{Author Notes}

Genelle K. Sawyer, PhD, is an assistant professor in the Department of Psychology at the Citadel. Her primary research interests include the assessment, treatment, and understanding of trauma and its consequences, particularly posttraumatic stress disorder.

David J. Hansen, $\mathrm{PhD}$, is professor of psychology and director of clinical training at the University of Nebraska-Lincoln. His primary research area is child maltreatment (sexual abuse, physical abuse, and neglect), including assessment and intervention with victims and families, and the correlates and consequences of maltreatment. 